\title{
Trabalhadoras(es) do SUAS: Quem são as(os) \\ Psicólogas(os) da Proteção Social Básica (PSB)
}

\author{
Roberta Fin Motta ${ }^{1}$ \\ ${ }^{1}$ Pontifícia Universidade Católica do Rio Grande do Sul, \\ RS, Brasil.
}

\author{
Catheline Rubim Brandolt ${ }^{2}$ \\ ${ }^{2}$ Universidade Federal de Santa Maria, \\ RS, Brasil.
}

\author{
Adolfo Pizzinato \\ ${ }^{3}$ Universidade Federal do Rio Grande do Sul, \\ RS, Brasil.
}

Resumo: Este estudo buscou apresentar elementos sobre a caracterização de psicólogas(os) do Sistema Único de Assistência Social (SUAS) e seus processos de inserção no nível de Proteção Social Básica (PSB) da cidade de Porto Alegre (RS), além de discutir as transformações no mundo do trabalho que, nas últimas décadas, têm atingido em maior grau a prática profissional no campo da política social. Participaram da pesquisa 27 profissionais; os dados foram obtidos por meio de entrevistas e construídos sob os princípios da Teoria Fundamentada (TF). Os resultados indicaram que as(os) trabalhadoras(es) estão submetidas a condições adversas de formação das relações de trabalho, desde o modo de contratação até o desenvolvimento das atividades rotineiras do trabalho. Por ser um campo em expansão, a materialização da atenção às necessidades sociais da população ainda carece de construções epistemológicas próprias para sua efetivação. A caracterização das(os) trabalhadoras(es) psicólogas(os) aponta inúmeros desafios para a construção de fazeres e saberes comprometidos com direitos sociais.

Palavras-chave: Trabalho, Psicologia, Sistema Único de Assistência Social, Centro de Referência da Assistência Social.

\section{Workers of Unique System of Social Assistance (SUAS): Who are the Psychologists at Basic Social Protection (PSB)}

\begin{abstract}
This study aimed to present elements about the insertion and characterization of psychologists of the Single Social Assistance System (SUAS) at the level of Basic Social Protection (PSB) in Porto Alegre, state of Rio Grande do Sul, Brazil, such as the changes in the world of work, which in recent decades have reached a higher level of professional practice in the field of social policy. Twenty-seven professionals participated and the data was collected through interviews and analyzed with the help of Grounded Theory (GT). The results indicate the workers are exposed to adverse conditions that are explicit in the personnel and work relations, starting at the hiring policies up to the development of routine activities at the SUAS (Social Assistance System in Brazil). Because this is a new and expanding field, it is emphasized through the data of the research the materialization that attention to the underprivileged populations still needs to be mediated for it to take place. The accounts of the psychologist point out the countless challenges to build a professional making that is compromised with social rights.
\end{abstract}

Keywords: Work, Psychology, Social Assistance System, Social Assistance Reference Center. 


\title{
Trabajadoras/es del Sistema Único de Asistencia Social (SUAS): Quiénes son las/los Psicólogas/os de la Protección Social Básica (PSB)
}

\begin{abstract}
Resumen: Este estudio propone identificar la caracterización de psicólogas/os del Sistema Único de Asistencia Social (SUAS) y sus procesos de inserción en el nivel de Protección Social Básica (PSB), en la ciudad de Porto Alegre (Rio Grande do Sul, Brasil), además de discutir las transformaciones en el mundo laboral que en las últimas décadas han alcanzado, en mayor grado, la práctica profesional en el campo de la política social. Participaron en la investigación 27 profesionales, y los datos han sido obtenidos por entrevistas y construidos bajo los principios de la Teoría Fundamentada. Los resultados indicaron que las/los trabajadoras/res están bajo condiciones adversas de formación y de las relaciones laborales desde las formas de contratación hasta las actividades rutinarias de trabajo. Por ser un campo en expansión, la materialización de la atención a las necesidades sociales de la población aún carece de construcciones epistemológicas propias para su efectividad. La caracterización de las/los trabajadoras/es psicólogas/os apunta numerosos desafíos para la construcción de haceres y saberes comprometidos con los derechos sociales.
\end{abstract}

Palabras clave: Trabajo, Psicología, Sistema Único de Asistencia Social, Centro de Referencia de Asistencia Social.

\section{Introdução}

Este artigo apresenta elementos sobre a caracterização de psicólogas(os) do Sistema Único de Assistência Social (SUAS) e seus processos de inserção no nível de Proteção Social Básica (PSB), além de ressaltar as transformações no mundo do trabalho que nas últimas décadas têm atingido em maior grau a prática profissional no campo da política social. Essas transformações repercutem diretamente no cotidiano de trabalho das(os) trabalhadoras(es) analisados, especificamente das(os) psicólogas(os) do Sistema Único de Assistência Social (SUAS) vinculadas(os) aos Centros de Referência de Assistência Social (CRAS) na cidade de Porto Alegre, estado do Rio Grande do Sul, Brasil.

Nas últimas décadas, a sociedade tem experienciado profundas alterações no interior do mundo do trabalho. Vivenciamos mais uma crise do capitalismo, e sua reestruturação produtiva tem provocado diversas consequências. Em meio às modificações conduzidas pela lógica de produção de mercadorias e de valorização do capital, podemos identificar o desemprego estrutural e o crescente número de trabalhadoras(es) em condições precarizadas, acarretando transformações materiais e subjetivas nas relações de trabalho contemporâneas (Alves, 2011).
A ampliação do mercado de trabalho vinculado às políticas sociais nos últimos anos, ainda que recente, abre possibilidades de inserção e atuação profissional da psicologia, bem como incorpora o trabalho precário, intensificando os processos e tencionando o fazer-saber da profissão, uma vez que o trabalho nas políticas sociais, e em especial na assistência social, não corresponde à perspectiva de trabalho que tradicionalmente caracteriza a profissão. Embora não se trate de aprofundar este tema aqui, precisamos destacar que, historicamente, as políticas sociais no Brasil, e especialmente a assistência social, são caracterizadas pela desregulamentação, flexibilização e precarização. Tais aspectos atingem também as relações de trabalho das(os) profissionais que atuam em instituições privadas e públicas vinculadas ao campo das políticas sociais, especialmente a partir dos anos 1990 sob o domínio da lógica neoliberal (Raichelis, 2011). Desta maneira, embora as relações de trabalho nas políticas públicas tenham se precarizado, as vagas para trabalhadoras(es) no SUAS ampliaram-se nos últimos anos (Motta, Castro, \& Pizzinato, 2015).

É neste panorama que também acontece a intensificação dos processos de inserção da psicologia nas políticas sociais públicas nas últimas décadas, de modo particular no campo da assistência social, a partir da 
implementação do SUAS. Tal progresso demonstra o reconhecimento da profissão no processo de consolidação da assistência social e a apropriação do fazer-saber psicológico como parte indispensável na proteção social básica (PSB). Contudo, ainda não temos a dimensão das características do trabalho, especificamente das(os) trabalhadoras(es) que atuam nos CRAS no Estado do Rio Grande do Sul e, mais estritamente, das(os) psicólogas(os) que exercem suas atividades na cidade de Porto Alegre no ano de 2014. Diante desse quadro, surge a necessidade de ainda se pesquisar sobre o trabalho enquanto campo de análise, considerando-se as transformações contemporâneas que assolam as(os) trabalhadoras(es), as(os) psicólogas(os) do SUAS, mais especificamente atuantes nos CRAS.

\section{Método}

O estudo é uma pesquisa qualitativa, de caráter exploratório, descritivo e analítico. Foram entrevistadas(os) 27 psicólogas(os) que atuam nos CRAS vinculados à Fundação de Assistência Social e Cidadania (FASC) no ano de 2014 na cidade de Porto Alegre, Rio Grande do Sul, Brasil. Quanto aos instrumentos $^{1}$ e procedimentos para a coleta das informações, optou-se pela entrevista ${ }^{2}$, contemplando a caracterização e o exercício profissional. As entrevistas foram realizadas, precedidas de explicação e esclarecimentos, e, após a leitura e a assinatura do Termo de Consentimento Livre e Esclarecido (TCLE), elas foram gravadas em áudio; depois de transcritas, foram desgravadas. Para preservar o anonimato e o sigilo foram adotados números como modo de identificação das(os) participantes. Para a análise das informações, utilizou-se a Teoria Fundamentada (TF) (Strauss \& Corbin, 2008). Apresenta-se uma descrição acerca de dados mais objetivos coletados entre as(os) trabalhadoras(es) no que se refere a suas características, como sexo, idade, escolaridade, formação complementar e cargo ocupado no momento do desenvolvimento da pesquisa; além disso, a forma de ingresso no CRAS, seu regime de trabalho, remuneração e o tempo de exercício profissional na assistência social. Desta forma, a pesquisa procurou responder à pergunta: quem são as (os) trabalhadoras(es) da psicologia atuantes nos CRAS? - tópico apresentado e discutido em maior profundidade a seguir.

\section{Resultados e Discussão}

Em relação às características das (os) entrevistadas (os), das(os) 27 participantes, 26 são mulheres, e 18 destas estão na faixa entre 23 e 39 anos. No que se refere à forma de ingresso, as(os) participantes destacaram o concurso público como modo principal de ingresso, assim como a oportunidade de acesso ao mercado de trabalho e a vontade de atuar na área como fatores para sua inserção. No tocante ao tipo de vínculo de trabalho, a maioria das(os) trabalhadoras(es) - 18 pessoas - está sem vínculo permanente, e 12 possuem pouco mais de alguns meses a 3 anos de experiência na função. No que se refere a uma formação complementar, 20 pessoas já a frequentaram ou frequentam no momento. A remuneração oscila entre cinco e seis para os concursados e entre três e quatro salários mínimos para terceirizados, o que denota a diferença salarial para funções e cargos equivalentes somente em função do vínculo trabalhista. No tocante à função, 19 participantes atuam como psicólogas(os) e oito assumem a função de coordenação de CRAS.

No que se refere à caracterização das(os) participantes em relação ao sexo, não encontramos discordância com os dados já registrados na literatura (Bastos, Gondim, \& Rodrigues, 2010; Leão, Oliveira, \& Carvalho, 2014; Macedo et al., 2011; Oliveira et al., 2014; Reis \& Cabreira, 2013; Seixas \& Yamamoto, 2012). Há um predomínio de mulheres: dos 27 participantes do estudo, apenas um é homem. A prevalência feminina também foi destaque na pesquisa organizada pelo Conselho Federal de Psicologia (Lhullier, 2013; Lhullier, Roslindo, \& Moreira, 2013): das (os) psicólogas (os) em exercício no Brasil, 89\% são mulheres. Este dado reafirma a perspectiva histórica feminina da profissão, como também acontece com outras profissões, como o serviço social, a enfermagem e a pedagogia, que atuam diretamente com o cuidado do outro e que se encaixam dentro das expectativas sociais impostas para cada gênero.

\footnotetext{
${ }^{1} \mathrm{O}$ instrumento foi adaptado de entrevistas e questionários desenvolvidos por Oliveira, Dantas, Solon e Amorin (2011), e Seixas e Yamamoto (2012).

22 As diretrizes para pesquisa com seres humanos para proteção dos direitos dos envolvidos foram respeitadas, conforme os aspectos éticos apontados pela Resolução em Pesquisa com Seres Humanos - no 466/2012, do Conselho Nacional de Saúde (2012). A pesquisa foi aprovada e autorizada pela FASC e pelo Comitê de Ética (CAAE: 2 26866814.6.0000.5336) de afiliação das (os) autoras (es).
} 
Aproveitamos o ensejo para discutir que tal tendência também aparece na própria Política Nacional de Assistência Social (PNAS), quando a operacionalização das ações, serviços, programas e projetos das políticas públicas no âmbito da assistência social elege como diretriz a centralidade na família e na mulher em sua condição de mãe, com o papel de "cuidadora" recaindo mais incisivamente sobre as mulheres pobres, as principais beneficiárias na PNAS. Nessa circunstância, a classe social se combina com a estrutura das relações sociais de gênero, o que pode contribuir para mudanças ou pode reforçar as desigualdades de gênero (Carloto \& Mariano, 2010). Nessa perspectiva, o estudo de Santos (2014) mostra que o sucesso dos programas sociais brasileiros depende, em grande parte, da atuação das mulheres, tanto como usuárias quanto como agentes sociais, mediadoras dentro da lógica conservadora da divisão sexual do trabalho e da disposição feminina para o cuidado. Sendo assim, os serviços prestados na assistência social centram-se essencialmente na dinâmica de mulheres e para mulheres, haja vista que a grande maioria das(os) usuárias(os) atendidas(os) foi e é constituída por pessoas do sexo feminino. Considerando-se o processo de feminização da profissão e a própria condição da mulher no país, os estudos que articulam gênero e trabalho podem ser um espaço de possibilidade de mudança e de transformação, destacando um tema que nos levaria a refletir e a consolidar novas formas de intervenção das(os) trabalhadoras(es) na política de assistência social. Podemos visualizar esse aspecto na fala da participante, a seguir:

A maioria das pessoas que vem aqui, as mães fazem bico no trabalho informal, não trabalham de carteira assinada, muitas delas não têm marido, vivem sozinhas com os filhos.... São as chefes de família, a maioria, se eu for olhar a lista de acompanhamento, $80 \%$ são mulheres que vivem com seus filhos, são elas que trabalham. ... Elas é que levam a comida, muitas delas nem procuram os direitos com relação à paternidade, à pensão ou benefício, não procura... (Participante 5).

Quanto à forma de ingresso, dentre os fatores que motivaram a escolha das(os) profissionais pela atuação no CRAS, destacaram-se três pontos: o primeiro, a oportunidade de inserir-se no mercado de trabalho; o segundo refere-se à garantia de estabilidade em um cargo que o funcionalismo oferece; e, por último, a vontade de trabalhar junto à área social, pelo fato de já ter vivenciado experiências na graduação por meio de estágios.

Nesta perspectiva, podemos inferir que as experiências obtidas na graduação podem contribuir para o desenvolvimento da capacidade crítica e reflexiva, uma vez que há um contato que oportuniza um modo distinto de ver e interpretar a realidade de grande parte da população brasileira, já que as(os) estudantes encontram-se mais próximas(os) das necessidades e demandas, colaborando também para a possibilidade de proposição de um projeto ético-político para a psicologia que seja crítico e progressista (Yamamoto, 2012).

Quanto à oportunidade de emprego na área, a descentralização das políticas sociais, em especial as de assistência social, tem contribuído para o aumento do quadro de profissionais nos municípios. Atrelada a isso, temos a implementação do SUAS em 2004, que impulsionou a inserção das(os) psicólogas(os) nos CRAS, CREAS e demais serviços vinculados à área em questão. Como caracterizam os dados do Censo SUAS (Secretaria Nacional de Assistência Social, 2015), neste período, o Brasil tinha 15.424 psicólogas(os), considerando-se os serviços em unidades públicas estatais e gestão do SUAS, o que evidencia um aumento significativo de trabalhadoras(es) nestes serviços. Todavia, é preciso considerar o contexto atual de desinvestimento nas políticas sociais, principalmente após a tramitação da Proposta de Emenda Constitucional (PEC) no55/2016, aprovada como Emenda Constitucional (EC) no 95/2016 e conhecida popularmente como PEC do Teto de Gastos Públicos. Além disso, destaca-se a aprovação da reforma trabalhista e da lei da terceirização em 2017. Diante destes movimentos, o percentual de trabalhadoras(es) da psicologia nos dispositivos que compõe o SUAS pode ter sido atingido em alguma proporção.

Ainda, de acordo com as(os) participantes, o concurso público também foi mencionado como uma das possibilidades de inserção, conforme revela a fala subsequente: "Foi uma investida em uma série de concursos que eu estava fazendo ... foram dois anos de estudos, investimento, porque eu queria sair da iniciativa privada..." (Participante 12).

Embora o setor público apresente "vantagens" como estabilidade, remuneração fixa e regime de aposentadoria, entre outros benefícios - o fato de se 
trabalhar em um órgão municipal, como é o caso do serviço em questão, não garante as mais dignas condições de atuação, já que esse setor também sofre os efeitos das transformações contemporâneas do trabalho, seja pela eliminação e/ou redução dos espaços, tanto no âmbito público quanto no privado, seja pela flexibilização das relações, dentre outros pontos que envolvem tais mudanças. De acordo com Druck (2016), na atualidade presencia-se uma nova precarização social do trabalho em que o caráter leva a uma regressão social em todas as dimensões do trabalho (empresas, indústrias, serviços públicos e privados, comércio).

Cabe ressaltar alguns pontos que dizem respeito à inserção da psicologia no contexto da política de assistência social. A entrada não partiu de uma profunda e sistemática reflexão crítica de caráter ético, político, conceitual, metodológico e profissional. A introdução deu-se em geral por questões mais circunstanciais, como o fato de ser uma categoria com amplo espectro de atuação e que pode contribuir com os diferentes níveis de complexidade da proteção social (Porto, 2007). Acrescentamos, também, o fato de que a prática, seu público-alvo, isto é, famílias em situação de vulnerabilidade e risco social, e suas demandas não correspondem à perspectiva de trabalho que historicamente caracteriza a profissão. Além destes, somam-se outros fatores, como a formação em psicologia. Seixas (2014), em sua pesquisa a respeito dos projetos pedagógicos de curso (PPC) de psicologia, refere que, apesar dos avanços na formação nos últimos anos - como a presença, nos fundamentos, do tema do compromisso social e da defesa de uma formação generalista, pluralista, multidisciplinar e com foco na pesquisa -, os currículos ainda continuam a oferecer às(aos) estudantes(os) "o ensino quase que exclusivo das áreas clássicas, com práticas profissionais que têm por base os campos tradicionais" (p. 238) com a ausência de temas ligados à realidade brasileira, apesar de as políticas sociais estarem presentes nos currículos de graduação.

Também é importante referir que a própria política de assistência social, especificamente nos documentos e manuais relativos aos CRAS, não trouxe uma clara definição das atividades que podem ser executadas no serviço e das ações pertinentes a cada profissional. Sabe-se que o trabalho social, como acolhida, estudo social ou visita domiciliar - bem como o restante das atividades preconizadas pela PNAS - se configura como essencial à execução das atividades na PSB (Secretaria Nacional de Assistência Social, 2004). No entanto, apesar da generalidade das ações, isso não implica que a singularidade não possa ser percebida, ou melhor, não possa ser revista diante das competências e habilidades de cada profissão, mesmo sendo um campo em que a multidisciplinaridade, a interdisciplinaridade e, quiçá, a transdisciplinaridade são postas como possibilidades de atuação. Além deste, somam-se outros fatores, como a capacitação e qualificação, e a própria gestão do trabalho no SUAS.

Os aspectos citados anteriormente podem contribuir na dificuldade de identificação e reconhecimento com a área e de realização profissional, uma vez que não houve envolvimento e, propriamente, debate sobre a inserção. Isto acaba incidindo no despreparo das(os) profissionais para o campo, visto as discrepâncias entre a formação, a necessidade de trabalho no âmbito das políticas sociais e o despreparo das(os) profissionais para enfrentar os desafios relativos a esse campo. A dificuldade em identificar o que seria de competência da psicologia aparece expressa na fala abaixo:

. . tu trabalha em equipe, mas tu não precisa fazer necessariamente o que o outro faz, cada um dentro da sua especificidade, e isso que eu vejo, tive que aprender muito da assistência e nem me formei para isso e aprendi como se faz o encaminhamento. ... Faço tudo, mas eu vejo que poderia contribuir muito mais dentro da assistência, se o psicólogo ficasse mais envolvido com os grupos, com as coisas que aparecem, reunir isso e esse daquele grupo que tu tem que desenvolver tal coisa com o familiar mesmo, mas não, a gente fica muito envolvido com burocracia, com papelada, com descumprimento. . . Eu acabo vendo que a gente tá fazendo exatamente a mesma coisa, na mesma hora, tem momentos que é necessário isso, mas não em todos os momentos e isso me desgasta muito, porque é uma percepção de perfil bem diferente, às vezes, da dupla (Participante 3 ).

No tocante ao tempo de exercício profissional, predominou o período de poucos meses até 3 anos, seguido de 3 a 6 anos de atuação profissional. Tal informação vincula-se a formações e contratações recentes, assim como coincide com o período em que a FASC, nos anos de 2010 e 2011, trabalhou no reordenamento 
institucional, conforme previsto na Tipificação Nacional de Serviços Socioassistenciais. Nesse período, iniciou-se a implantação dos CRAS e CREA na cidade $^{3}$. As informações elencadas quanto ao tempo de exercício profissional também vão ao encontro das informações coletadas nas pesquisas de Oliveira et al. (2011), Seixas e Yamamoto (2012), Macedo e Dimenstein (2012), Reis e Cabreira (2013), Leão et al. (2014) e Oliveira et al. (2014). Podemos nos questionar no sentido de que, em comparação com outros municípios e com outros contextos do Brasil e da própria política de assistência social, a implantação dos CRAS e CREAS em Porto Alegre foi tardia. Há, ainda, um número significativo de psicólogas(os) jovens, com inserção recente na assistência social e que estabelecem cotidianamente fazeres-saberes numa política também recente e em constituição. A atividade, então, acaba se configurando como transitória e de travessia para outras políticas e/ou outras atividades profissionais, principalmente em decorrência da precarização do trabalho que acomete os serviços da área e que se destaca nas narrativas ao longo do texto.

Em relação ao tipo de vínculo de trabalho, a configuração com maior incidência é o de trabalhadoras(es) sem vínculo permanente (18), seguidas(os) pelas estatutárias(os) (9). Tais resultados nos mostram que a maioria das(os) profissionais que atuam nos CRAS não tem vínculo permanente, o que corrobora com os demais estudos de Oliveira et al. (2011), Macedo et al. (2011), Seixas e Yamamoto (2012), Macedo e Dimenstein (2012), Leão et al. (2014) e Oliveira et al. (2014). Em particular, citamos o estudo de Senra e Guzzo (2012), que destaca a contratação por meio de organizações não governamentais (ONG) em determinados municípios, sob a justificativa de impedimentos fiscais e legais e em razão da ausência de concursos públicos, situação do município foco da pesquisa. De acordo com o Censo SUAS (2015), 28.493 (29,9\%) são servidoras(es) estatutárias(os), empregadas(os) públicas(os) (CLT) são 6.495 (6,8\%), enquanto as(os) comissionadas(os) são 9.435 (9,9\%). Outros vínculos não permanentes somam 50.902 (53,4\%). Tais dados refletem a situação das(os) trabalhadoras(es) dos CRAS pesquisados.

O fato de existirem diferentes tipos de vínculos empregatícios num mesmo local de trabalho foi um dos pontos que permearam as falas das (os) trabalhadoras (es), o que ressalta as peculiaridades entre servidoras(es) públicas(os) e profissionais contratadas(os) por meio da terceirização. Dessa forma, tem-se observado que, cada vez mais, os governos optam por uma administração dividida entre setor público e privado, ou seja, pela terceirização na contratação das(os) trabalhadoras(es) por meio de cooperativas, fundações e entidades filantrópicas. Tal circunstância pode acabar por fomentar e/ou criar uma divisão de categorias dentro do ambiente de trabalho a partir do estabelecimento de grupos de trabalho marcadamente desiguais, como, por exemplo, de concursadas(os) - servidoras(es) públicas(os) -, por um lado, e contratadas(os) por empresas/instituições terceirizadas, por outro. Druck (2013) menciona que este fator é percebido como uma dimensão qualitativa da terceirização, pois pode potencializar as diferenças entre a equipe de referência e refletir no desenvolvimento e no comprometimento com o trabalho.

A relação estabelecida no âmbito da assistência social de caráter público-privado pode ser compreendida como uma estratégia que impede a adesão das(os) trabalhadoras(es) junto ao trabalho - o que dificultaria a reivindicação por melhorias em suas condições (Bernardo, Verde, \& Pinzón, 2013). A falta de investimentos em infraestrutura e as sucessivas mudanças administrativas também são fatores que contribuem para uma situação de incerteza quanto à permanência no serviço (Senra \& Guzzo, 2012). Corroborando com essa perspectiva, Alves (2011, p. 39) afirma que a "nova morfologia social do trabalho" - caracterizada "por dinâmicas psicossociais que implicam a dessubjetivação de classe, a captura da subjetividade da(o) trabalhadora(or) assalariada(o) e a redução do trabalho vivo à força de trabalho como mercadoria" sob o capitalismo flexível - espalha a insegurança (e a incerteza) de contratos de trabalho flexíveis, impedindo a organização de espaços de interação social, o que incide na qualidade dos serviços prestados e nos vínculos de solidariedade entre as(os) trabalhadoras(es).

Outra questão abordada pelas(os) profissionais foi a respeito das capacitações. Pode-se dizer que a terceirização age como objeto de discriminação laboral. Podemos observar isso no trecho abaixo:

\footnotetext{
${ }^{3}$ Em 2011, foi implantado o SUAS no município, por meio do Decreto no 17.256, de 05/09/2011 e, em 2013, foi aprovado o Regimento Geral e Novo Organograma da FASC, por meio do Decreto 18198, de $1^{\circ}$ de fevereiro de 2013 (Prefeitura de Porto Alegre, 2013).
} 
... "Ah porque a(o) coordenador(a), quando tem alguma coisa, algum curso, alguma capacitação, prefere levar a (o) colega do quadro e não a(o) técnica(o) da terceirizada, "ah, porque tem diferença", essa distinção assim, "ah, mas tu és técnica(o) da terceirizada", "ah, mas tu és do quadro"(Participante 3 ).

No âmbito do trabalho também se identifica a rotatividade de profissionais, o que implica um desperdício de recursos e tempo em capacitação, considerando-se os constantes recomeços com novas demandas de qualificação para a mesma função, bem como o rompimento do vínculo com as famílias e as(os) demais integrantes da equipe. Tal questão fica evidente na fala a seguir: "Então, uma das nossas dificuldades é a rotatividade da equipe, que toda vez que entra alguém eu tenho que fazer tudo de novo, né, conhecer os territórios ..." (Participante 16). Com este dado, é possível denotar mais uma contradição, visto que o serviço do CRAS tem o intuito de promover o fortalecimento dos vínculos familiares $\mathrm{e}$ comunitários e, para isso, é importante que se priorize a noção de continuidade e de estabelecimento de laços de confiança e de acolhimento dos profissionais da equipe para com as famílias acompanhadas.

Algumas(ns) participantes ressaltaram determinadas atitudes das(os) servidoras(es) públicas(os) de modo a reforçar a ideologia de que a(o) servidora(or) pública(o) é acomodada(o) e que cumpre apenas o estritamente necessário etc. Talvez, em alguns casos, isso possa acontecer de fato, como podemos observar na fala a seguir da(o) participante 19. Contudo, é importante nos darmos conta de que, segundo Raichelis (2011), a propagação do ideário neoliberal comprometeu a imagem da(o) servidora(or) públi$\mathrm{ca}(\mathrm{o})$ e suas representações sociais junto à população, como se observa na fala a seguir: ... porque a gente faz a mesma coisa . ... E às vezes a gente vê, assim, que a gente faz até mais, que as pessoas estão acomodadas, porque estão estabilizadas, e tu está ali, precisando desse emprego, trabalhando... (Participante 19).

Atrelada aos aspectos relacionados ao vínculo empregatício, a remuneração configura-se como mais um dos itens que se adiciona à precarização do trabalho nas políticas públicas. As(Os) servidoras(es) públicas(os) concordam que a média salarial condiz com o mercado de trabalho. Contudo, no que se refere ao plano de cargos ou carreira há concordância quanto à necessidade de melhorias, conforme podemos visualizar na próxima fala:
Eu acho bom o salário. Comparando com a média do mercado, acho bem bom .... A questão de plano de carreira...é bem ruim, é bem ruim! A gente não tem plano de saúde. Cada um tem que fazer uma estratégia, pegar do marido ou pagar um por fora, porque a gente não tem. Plano de carreira é muito dificil de conseguir . ... É uma coisa que é ruim, bem ruim, é uma desvalorização (Participante 14).

Ainda fica manifesta a remuneração diferenciada para funções e cargos equivalentes, uma vez que as(os) terceirizadas(os) ganham menos que as(os) servidoras(es) públicas(es) e que seus contratos não asseguram garantias ou benefícios trabalhistas. Consequentemente, desenvolvem-se comparações inevitáveis entre servidoras(es) públicas(es) e terceirizadas(os), o que pode provocar significativas alterações no cotidiano de trabalho, conforme os relatos das(os) entrevistadas(os): Tu não tem noção, pra ti ter uma ideia, a gente ganha menos da metade do que elas(es) ganham. ... . O mínimo delas é o dobro ... . É muita diferença, é demais e isso dói um pouco ... (Participante 5).

Outro ponto diz respeito à necessidade das(os) profissionais complementarem sua renda. Evidentemente, diante da precariedade, a remuneração se reduz, o que pode justificar a opção por mais de um emprego com o intuito de se complementar a renda, conforme explicitado na fala a seguir:

eu atendo uma vez por semana, mas mais assim, porque eu necessito do dinheiro, não por desejar, por gostar, não, eu gosto é daqui, é disso aqui, é dessa gente, é dessas pessoas, é do contato, é de poder estar aqui ... (Participante 5).

Quanto à remuneração, de uma forma geral, houve um retrocesso ao longo das últimas décadas. Isso é um indício de que, apesar da inserção e ampliação do campo de atuação profissional, poucas(os) obtêm rendimentos mais elevados. Isto apoia a denúncia de precarização das demais condições de trabalho, pois elas frequentemente acompanham os processos de redução da remuneração (Macêdo, Heloani, \& Cassiolato, 2010). Na conjuntura da precarização, recorremos a Macedo e Dimenstein (2012), quando apontam que as(os) profissionais que têm como objetivo garantir o desenvolvimento de ações vinculadas à seguridade social são as(os) mesmas(os) que se encontram descobertos em seus direitos e 
garantias. Atualmente, a diversidade de vínculos de trabalho marca o exercício profissional, assim como o número expressivo de crescimento de profissionais assalariados na psicologia. De acordo com a pesquisa realizada por Macêdo et al. (2010), o número de profissionais com algum vínculo salarial supera o daqueles que são exclusivamente autônomos. Ainda, ressaltam as(os) autoras(es), o trabalho assalariado é marcado pela variedade de setores, com ligeiro predomínio de inserção nos serviços públicos.

Nessa perspectiva, sabe-se que ao longo das últimas décadas, houve a substituição gradual e progressiva do trabalho autônomo pelo trabalhado assalariado. Contudo, reforçamos que ainda devem ser discutidas as reverberações que surgem dessa trajetória, uma vez que ela, até pouco tempo atrás, não condizia historicamente com a atuação profissional da psicologia. Ademais, devemos reiterar que, além de constituir-se como uma(um) trabalhadora(or) assalariada(o), a categoria faz parte de um extrato profissional que historicamente contribuiu para a manutenção da ordem social e, ao inserir-se em uma política pública que lida basicamente com a efetivação da garantia de direitos de qualquer cidadã(o) que dela necessita - prioritariamente, as(os) cidadãs(ãos) que estão em pobreza -, vê-se diante de muitos desafios. A respeito disso, Oliveira e Amorim (2012) ressaltam as dificuldades advindas do trabalho com a pobreza, adicionadas ao enfrentamento de um campo impregnado por embates políticos, pelo mau uso da máquina pública e com pouco direcionamento técnico. Essas questões expostas, vinculadas ao sentimento de insegurança, podem vir a contribuir para a perda do caráter humano que direciona a atuação da profissão na assistência social no sentido de este ser um trabalho criador, criativo, educativo e emancipatório. Em relação aos pontos abordados anteriormente, percebe-se possibilidades, ou seja, movimentos micropolíticos aparentes no cotidiano de trabalho e que tentam buscar melhorias de condições para todas(os), conforme a fala descrita a seguir:

... a gente tenta criar um clima que todo mundo é CRAS, todo mundo é funcionário do CRAS, e que não tem diferença se tu tens o primeiro grau completo ou se tem terceiro, pós-graduação, né, fulano. ... a gente vai horizontalizar isso, né. Não tem, é todo mundo no mesmo nível. ... São todos pessoas... (Participante 16).
Nessa perspectiva, recorremos a Prates (2014), que refere que é preciso trabalhar para o desenvolvimento da percepção de que os processos são coletivos e precisam ser enfrentados coletivamente. Deve-se, portanto, desenvolver a solidariedade para além da solidariedade despolitizada, reduzida, capturada pelo capital, adentrando nos âmbitos dos processos de trabalho desde os lugares de gestão e planejamento até a execução terminal de políticas, trabalhando com dados fundamentados por teorias explicativas e construindo alianças com outras(os) trabalhadoras(es) e com a população usuária dos serviços.

Quanto à formação complementar, as(os) participantes, em sua grande maioria, já frequentaram ou estão frequentando um curso de pós-graduação, seja especialização (17 pessoas), seja mestrado (uma pessoa), seja residência multiprofissional em saúde (duas pessoas). O título de especialização é a qualificação profissional que as(os) participantes mais possuem, conforme descrito também nas pesquisas de Macedo e Dimenstein (2012), Seixas e Yamamoto (2012), Reis e Cabreira (2013) e Leão et al. (2014). Apenas seis profissionais, no momento da pesquisa, não estavam cursando nenhuma especialização. Dentre as formações complementares elencadas pelas(os) participantes, podemos dizer que estas vão desde as em psicanálise e as na áreas das saúde, e das organizações e do trabalho, até as formações nas áreas da família, da educação, da avaliação psicológica e na área social. As áreas clínica e da psicologia da saúde, seguidas da psicologia organizacional e do trabalho estão entre os maiores campos de atuação dos psicólogos (Conselho Federal de Psicologia [CFP], 2003). Podemos ressaltar a questão de que não existem muitos cursos de pós-graduação no campo das políticas sociais, mas mesmo as(os) trabalhadoras(es) já inseridas(os) e atuantes na área da assistência social optam por ter a formação complementar em uma área considerada mais tradicional. Tal afirmação, referente às investigações no Rio Grande do Norte (Seixas \& Yamamoto, 2012), estende-se à pesquisa em questão. E, por último, mas não menos importante, referimo-nos ao contexto econômico com diretrizes neoliberais em que vivemos, que trouxe novas exigências para o mundo do trabalho já elencadas anteriormente e que fez surgir um novo perfil de trabalhadora(or), cada vez mais solicitada(o) a se especializar continuamente para atender às novas demandas do mercado de trabalho (Heloani et al., 2010). Desta 
forma, podemos inferir que a capacitação profissional tem se apresentado como condição necessária para compor a qualificação profissional, de forma a haver uma complementaridade entre a formação generalista e a especialização.

Por meio das informações coletados, estabelecemos a distribuição das funções. Dentre as(os) participantes da pesquisa, identificamos que oito exerciam a função de coordenadoras(es) e que 19, a função psicólogas(os) e técnicas(os) sociais. É importante ainda salientar a presença de psicólogas(os) como coordenadores dos serviços, ou seja, como parte integrante da gestão na assistência social nos CRAS da cidade de Porto Alegre. A função exercida no âmbito da gestão é algo recente e que denota desafios, conflitos e possibilidades do fazer-saber, principalmente por ser uma função exercida em geral pelas(os) profissionais do serviço social e por constituir uma prática que não corresponde à perspectiva de trabalho que caracteriza a profissão. Macedo et al. (2011), em sua pesquisa, evidenciam, a respeito da ocupação na função de coordenadora(or) que a região Sudeste apresentou o maior número de coordenadoras(es) psicólogas(os) que trabalhavam nessa condição. Nas últimas décadas, em virtude das transformações do mundo do trabalho, particularmente a partir de 1990 em consequência da reforma neoliberal do Estado, mudanças ocorreram e estabeleceram-se novas formas de trabalho. Modificaram-se as formas de gestão, o que alterou profundamente os processos de gestão do trabalho. Tal cenário afeta o andamento das atividades, o direcionamento dos resultados para a população assistida, assim como define fragilidades e possibilidades de vida no cotidiano de trabalho na assistência social. Falar em gestão do trabalho, especificamente na assistência social, não é uma tarefa fácil, visto que os estudos são escassos e incipientes, muito embora Couto, Yazbek, Silva e Raichelis (2010) reafirmem que a discussão sobre a construção de uma política de recursos humanos é percebida atualmente como um dos eixos estruturantes do SUAS.

As(os) psicólogas(os) têm sido interpeladas(os) a assumir a coordenação dos CRAS. Ao mesmo tempo em que isso demonstra o reconhecimento e a valorização do trabalho das(os) profissionais no processo de consolidação da assistência social, configura-se também como um desafio que preocupa pela maneira como está acontecendo. As(Os) profissionais que adentraram a coordenação dos CRAS relatam que não tiveram formação para tal, seja na graduação seja no próprio sistema, sobre planejamento e gestão, conforme ilustra a fala a seguir: ... eu problematizo isso, acho que o curso de psicologia não te proporciona esta cadeira de gestão, não problematiza isso em lugar nenhum... (Participante 16).

Ao mesmo tempo, percebe-se, pelas falas das(os) participantes que, de certa forma, a formação em psicologia contribui para a prática de trabalho da coordenação, como de acordo com a seguinte fala:

. . . acho que a gente tem muitas condições, né, de assumir a coordenação dentro da assistência, porque não sei se sou eu que gosto muito de ser psicóloga, gosto muito da nossa profissão... Eu acho que a gente tem uma visão muito ampla de tudo e então poder conhecer o SUAS na teoria, estudar, aprender um pouco e também me colocar nesse papel da coordenação, dentro da assistência. . . . Então eu vejo que a nossa profissão nos ajuda muito, assim, nos dá uma ferramenta muito grande (Participante 18)

Podemos afirmar que a temática da gestão não se encontra, de fato, nos currículos da graduação em psicologia, mas apenas em algumas disciplinas da área vinculadas às organizações e ao trabalho, embora seja abordada com um enfoque outro que não o de instruir o profissional para tal função. Esse distanciamento da função talvez possa ser confirmado em virtude de que ainda carregamos a representação daquela(e) profissional que conserta, corrige, adapta, isto é, que se torna privilegiado por exercer a prática curativa, individual, diagnóstica, assistencialista e especializada. Atrelado a esse fato, podemos pensar que nos constituímos como uma profissão liberal, assim como - pelas Atribuições Profissionais do Psicólogo, referidas pelo Ministério do Trabalho para integrar o Catálogo Brasileiro de Ocupações ${ }^{4}$ - não temos, como princípio fundante da profissão, a gestão. Ainda nessa perspectiva, vemos, na fala de uma(um) das(os) coordenadoras(es) que ela(e) não se percebe como profissional da psicologia no momento em exerce a função de gestão, mas apenas quando discute os assuntos que entende dizer respeito ao fazer psicológico.

${ }^{4}$ Conselho Federal de Psicologia. Atribuições profissionais do psicólogo no Brasil, s.n. 
. . mas eu gosto dessa parte mais operacional, de planejamento. Eu invento as coisas na minha cabeça, eu leio coisas na internet, assim, bem na parte do planejamento estratégico, assim, e a parte da gestão de equipe também. E eu acho bem bom. Não tem muito problema, assim, com tabela e números, embora eu diga: eu não sou psicóloga, sabe, é um trabalho bem diferente dos psicólogos. Nas discussões de casos eu me sinto psicóloga, mas no dia a dia da gestão, não (Participante 14).

A função de coordenação de um CRAS é mais uma possibilidade do fazer da psicologia que se apresenta na operacionalização da política de assistência social a partir das competências e habilidades em conjunto com o conhecimento da própria política, da legislação e em consonância com o que é esperado para a função de acordo com a indicação institucional:

... ser psicóloga e ser coordenadora é perfeitamente compativel, e a função de coordenadora me permite criar essa ambiência, criar essa possibilidade de trabalho lá onde eu estou. ... Então, tem todas essas partes, é técnico, é administrativo, mas é o psicólogo que tá ali, faz diferença que seja o psicólogo que esteja nesse lugar. O que não é nem melhor nem pior do que se fosse o pedagogo ou o assistente social, né? Mas tem a sua diferença (Participante 6).

Desta forma, se reforça a necessidade da inserção de disciplinas que discutam e capacitem para a gestão do trabalho e para gestão dos serviços nos cursos de formação em psicologia, assim como de espaços de escuta e reflexão crítica, que possibilitem o exercício da função de coordenação. Sobre o trabalho da(o) gestora(or), Gaulejac (2007) afirma que ela(e) interioriza, mais do que qualquer outra pessoa, as contradições entre o capital e o trabalho, uma vez que, de um lado, é convocado a identificar-se com os interesses da instituição empregadora de modo interiorizar a lógica capitalista e aderir às normas e valores do sistema e, de outro, está submetida(o) às imprevisibilidades da carreira, à pressão do trabalho e a uma forte competição em um campo que é, também, eminentemente relacional. Desta forma, consideramos a função de coordenação dos CRAS um desafio para o fazer-saber em psicologia ao mesmo tempo em que se configura como mais uma oportunidade. Por mais que estejamos ou nos sintamos engolfadas(os) pelo sistema, sempre haverá alternativas em termos teóricos e práticos, pautados por princípios éticos e por um olhar humanizado sobre o mundo que cruze os níveis macro e micro na ação e na reflexão crítica. Tal função pode proporcionar, também, a possibilidade de produzir a gestão da invenção e da criação a partir da relação com outras(os) profissionais, usuárias(os) e gestoras(es) presentes no cotidiano dos CRAS.

Ademais, um dos aspectos que nos chamou a atenção foi o fato de que algumas(ns) profissionais desejam sair do CRAS para ocupar o cargo em um outro serviço da área da assistência social, como em CREAS e em acolhimentos institucionais, por exemplo.

... e se eu voltaria, eu voltaria para o CREAS, né, eu optaria pelo CREAS, eu gosto de trabalhar no CRAS enquanto técnica(o), mas o desafio do trabalho no CREAS, hoje, em Porto Alegre, me chama muito a atenção ... porque hoje elas(es) não trabalham com grupos... tem um planejamento em Porto Alegre que ele é individual . . que ganha uma escuta sistemática... (Participante 16).

Do mesmo modo, algumas(ns) trabalhadoras(es) mostram-se motivadas(os) a deixar a assistência social para a área da saúde, basicamente:

... desde que eu me formei, eu trabalhei na área da saúde pública, tanto que eu amo a saúde, eu quero voltar, não quero seguir carreira na assistência, mas eu aprendi muito, agradeço muito, mas tenho éoutro enfoque, certeza de que vou voltar na saúde com visões de coisas que passavam despercebidas, que não eram importantes, desconhecidas, né... (Participante 2).

A partir da motivação para migrar para serviços especializados da saúde ou para outros dispositivos da assistência social, podemos inferir que há uma questão-chave: no que se refere à modalidade de atendimento, tanto no CREAS quanto nos serviços vinculados à saúde, práticas mais tradicionais da psicologia aplicada, como a clínica tradicional, integram as atividades das(os) profissionais que lá atuam. O primeiro refere-se à especificidade da proteção social especial (PSE) no CREAS que, devido à natureza e ao agravamento das situações de risco pessoal ou social, implica um acompanhamento especializado, individualizado, continuado e articulado com a rede. Embora no campo da saúde, nos últimos anos, tenham ocorridas 
transformações em relação à prática profissional, ainda é possível notar uma atuação direcionada aos moldes tradicionais da clínica do modelo liberal-privatista de cunho individual e curativista que fomenta o ideário que historicamente caracteriza a profissão.

Face ao exposto, trazemos ao debate o fato de que na psicologia existem distintas subáreas reconhecidas que possuem expectativas, formas de produção, métodos e, como ousam afirmar alguns, epistemologias distintas, e que, por isso, essa discussão se torna ainda mais complexa. De acordo com Lopes (2009), todo projeto consistente de psicologia científica tem que enfrentar pelo menos duas ameaças: ou ela se aproxima da ciência clássica e perde seu objeto e sua especificidade ou, quando se aproxima do que parece ser seu objeto, acaba por abandonar os métodos tradicionais. Em suma, ora é psicologia não-científica, ora é ciência não-psicológica (Figueiredo, 2003).

Ao campo teórico, soma-se a insegurança do emprego, as precárias formas de contratação, a intensificação do trabalho, o aviltamento dos salários, a pressão pelo aumento da produtividade e por resultados imediatos, a ausência de horizontes profissionais de mais longo prazo, a falta de perspectivas de progressão e de ascensão na carreira, a ausência de políticas de capacitação profissional, entre outros fatores (Raichelis, 2011).

Cabe ressaltar que não é nossa intenção propor algo no sentido de que não existam mais as práticas tradicionais, mas, de certa forma, refletir para que possamos dialogar com outros modos de realizar a clínica, sugerindo que esta tenha um caráter ampliado, conforme preconizado nas políticas sociais. Desse modo, torna-se importante visualizar e discutir os conceitos de clínica trabalhados, uma vez que a inserção nas políticas públicas provocou, de uma forma geral, uma desconstrução na marca que caracteriza a profissão e que ainda produz implicações na atuação e na formação em psicologia.

Ainda tivemos a oportunidade de ouvir profissionais que, antes de adentrar na assistência social, aspiravam por trabalhar em outra área e/ou local originalmente e que hoje não desejam retomar esses planos. É o que se pode destacar na fala a seguir:

Quando eu cheguei aqui eu nem sabia o que era assistência social, eu levei um choque, porque eu sempre trabalhei em consultório e escola, eu nunca tinha trabalhado com assistência ... hoje em dia eu vou te dizer que eu não troco isso aqui por nada desse mundo.... "A minha vida mudou depois que eu comecei a acessar o CRAS, eu sou outra pessoa". Isso, para mim, não tem nada que me pague mais do que isso. Isso, para mim, é a moeda. Eu não sei, eu descobri isso depois de ter me formado. Eu já estava seis, sete anos formada e eu descobri esse amor (Participante 5).

O fato de algumas(ns) psicólogas(os) se identificarem e desejam continuar na assistência social sinaliza para a abertura de novas possibilidades de inserção, atuação e formação em psicologia que tenham a perspectiva de desenvolver um projeto coletivo que opera junto ao trabalho na assistência social. Nesse sentido, não haveria exagero em afirmar que a inserção da psicologia nas políticas sociais públicas deve-se às transformações sociais e políticas no Brasil, marcadas pelo neoliberalismo e pelo aumento do processo de exclusão social desencadeado por essas mudanças que fizeram a psicologia questionar se a área estava formando profissionais voltados para as reais necessidades da sociedade brasileira (CFP, 2009).

\section{Considerações finais}

A assistência social constitui-se um campo novo de atuação para as(os) profissionais de psicologia. As(Os) psicólogas(os) adentram este espaço de trabalho em função de uma oferta de mercado na área em razão da expansão e da interiorização dos serviços da assistência social, assim como pelas "vantagens" que o concurso público oferta e, em alguns casos, pela vontade de atuar na área.

As(Os) profissionais têm encontrado a possibilidade de exercício profissional e, portanto, são convocados não por sua formação específica propriamente dita em políticas públicas, mas pela condição de trabalhadoras(es). Desta forma, a partir da análise dos resultados encontrados, estes não divergiram do apontado a respeito da inserção e prática da psicologia nos CRAS em pesquisas anteriores. Assim como no panorama nacional, as(os) profissionais estão inseridos em um cenário carregado de exigências impostas pelo modelo neoliberal de trabalho e são atingidas(os) e submetidas(os), como trabalhadoras(es) assalariadas(os), às determinações institucionais pela dinâmica de flexibilização/precarização nos diferentes espaços que ocupam. Essa(e) mesma(o) trabalhadora(or) também é afetada(o) por esse cenário como profissional comprometida(o) com a efetivação da garantia dos direitos sociais a partir das reformas neoliberais que emergiram a partir dos anos de 1990. 
Apresenta-se no contexto da pesquisa um número significativo de psicólogas(os) jovens, na maioria mulheres, com inserção recente na assistência social e que estabelecem cotidianamente fazeres-saberes numa política também recente e em constituição, destacando-se como uma trajetória transitória e de travessia para outras políticas e/ou outras atividades profissionais, configurando-se como possibilidade de construir pontes para outros espaços até que outras possibilidades surjam.

Este indicativo acena para o despreparo das(os) profissionais para o campo, visto as discrepâncias entre a formação, a necessidade de trabalho no âmbito das políticas sociais e a inexperiência das(os) trabalhadoras(es) para enfrentar os desafios relativos a esse campo. Tais aspectos podem contribuir para a dificuldade de identificação e de reconhecimento com a área e para a realização profissional. Percebe-se o número muito incipiente de formações na área, o que pode conduzir à realização de formações complementares em campos já reconhecidos e tradicionais na categoria. No entanto, quando essas formações são oferecidas, elas em geral são proporcionadas pela instituição estatal e vê-se então que as(os) terceirizadas(os), em alguns casos, acabam sendo preteridos em favor das(os) profissionais que estão na condição de trabalhadoras(es) do quadro, ou seja, de servidoras(es) públicas(os).

Ainda nessa perspectiva, outro aspecto a frisar diz respeito ao vínculo de trabalho, em que se evidenciou que a maior incidência é a de trabalhadoras(es) sem vínculo permanente, existindo distinções nos salários, garantias e benefícios entre servidoras(es) públicos e as(os) profissionais contratados por meio da terceirização. Também é importante salientar a presença de psicólogas(os) na função de coordenação dos serviços e como parte integrante da gestão no SUAS, o que coloca a necessidade de se estar ainda mais atento para qualificar esse trabalho.

Muito embora o foco deste artigo esteja na psicologia, é importante ressaltar que as adversidades, os desafios e as possibilidades discutidos ao longo do trabalho não se referem ou dizem respeito apenas as(aos) psicólogas(os). Claro que não se dever deixar de apontar as especificidades pertinentes a cada profissão, mas as formas de profissionalidade, como aponta Bourdoncle (1991), estão associadas às instabilidades e ambiguidades que envolvem o trabalho em tempos neoliberais, assim como Vasconcelos (2011) reforça serem tais provocações fundamentais também para as(os) demais profissionais que atuam na área. Tal cenário afeta o andamento das atividades e o direcionamento dos resultados para a população assistida, assim como define fragilidades e possibilidades de vida no cotidiano de trabalho na assistência social.

Desta maneira, pautas antigas e diversas começam a (re)surgir no campo da assistência social. Dentre elas, estão o debate sobre a formação em psicologia e as relações entre trabalho e saúde, além das repercussões advindas da vida das(os) trabalhadoras(es) como decorrência dos processos de precarização e intensificação a que estão submetidas(os) no ambiente de trabalho. Trata-se de temas que precisam ser mais conhecidos e debatidos, e que exigem um amplo programa de pesquisa para dar conta da amplitude da temática e das diferentes dimensões envolvidas com o intuito de valorização, reconhecimento e melhoria das condições de trabalho para se atuar nos CRAS. Do contrário, alerta Nery (2009), a consolidação do SUAS poderá se configurar de maneira frágil e inconclusa. A autora ainda complementa que o SUAS somente conseguirá se implantar, de fato, se tivermos profissionais selecionadas(os) por meio de concurso público, com contratos de trabalho que garantam mais estabilidade e que fortaleçam o vínculo empregatício, bem como qualificados tecnicamente e quantitativamente instalados em espaços condizentes com as demandas da população e com a complexidade do trabalho realizado nos serviços. Nessa perspectiva, recorremos, por fim, a Sposati (2007, p. 104), quando diz que: "recursos humanos na gestão da Assistência Social é matéria - prima e processo de trabalho fundamental. A Assistência Social não opera por tecnologias substitutivas ao trabalho humano".

\section{Referências}

Alves, G. (2011). Trabalho flexível, vida reduzida e precarização do homem-que-trabalha: perspectivas do capitalismo global no século XX. In A. L. Vizzaccaro-Amaral, D. P. Mota, \& G. Alves (Orgs.), Trabalho e saúde: A precarização do trabalho e a saúde do trabalhador no Século XXI (pp. 39-55). LTr.

Bastos, A. V. B., Gondim, S. M. G., \& Rodrigues, A. C. A. (2010). Uma categoria profissional em expansão: Quantos somos e onde estamos? In A. V. Bastos, \& S. M. Gondim (Orgs.), O trabalho do psicólogo no Brasil (pp. 32-44). Artmed. 
Bernardo, M. H., Verde, F. F., \& Pinzón, J. G. (2013). Vivências de trabalhadores com diferentes vínculos empregatícios em um laboratório público. Cadernos de Psicologia Social do Trabalho, 16(1), 119-133. https://doi.org/10.11606/ issn.1981-0490.v16ilp119-133

Bourdoncle, R. (1991). La professionnalisation des enseignants : Analyses sociologiques anglaises et américaines. Révue Française de Pédagogie, 94, 73-91.

Carloto, C. M., \& Mariano, S. A. (2010). No meio do caminho entre o privado e o público: Um debate sobre o papel das mulheres na política de assistência social. Revista Estudos Feministas, 18(2), 451-471.https://doi.org/10.1590/ S0104-026X2010000200009

Conselho Federal de Psicologia. (2003). Resolução $n^{\circ} 13$ de 2007. Institui a Consolidação das Resoluções relativas ao título profissional de especialista em Psicologia e dispõe sobre normas e procedimentos para seu registro. Conselho Federal de Psicologia.

Conselho Federal de Psicologia. (2009). Serviço de Proteção Social a Crianças e Adolescentes Vítimas de Violência, Abuso e Exploração Sexual e suas Famílias: Referências para a atuação do psicólogo. Centro de Referência Técnica em Psicologia e Políticas Públicas.

Conselho Nacional de Saúde. (2012). Resolução no 466, de 12 de dezembro de 2012. Conselho Nacional de Saúde.

Couto, B. R., Yazbek, M. C., Silva, M. O. S., \& Raichelis, R. A. (2010). O Sistema Único de Assistência Social no Brasil: Uma realidade em movimento. Cortez.

Druck, G. (2013). A precarização social do trabalho no Brasil. In R. Antunes (Org.), Riqueza e miséria do trabalho no Brasil II (pp. 55-73). Boitempo.

Druck, G. (2016). A indissociabilidade entre Precarização Social do trabalho e Terceirização. In M. O. Teixeira, \& E. Coelho (Orgs.), Precarização e terceirização: Faces da mesma realidade (pp. 35-58). Sindicato dos Químicos.

Figueiredo, L. C. M. (2003). Matrizes do pensamento psicológico. Vozes.

Gaulejac, V. (2007). Gestão como doença social: Ideologia, poder gerencialista e fragmentação social. Ideias \& Letras.

Heloani, R., Macêdo, K. B., \& Cassiolato, R. (2010). O exercício da profissão características gerais da inserção profissional do psicólogo. In A. V. Bastos, \& S. M. Gondin (Orgs.), O trabalho do psicólogo no Brasil (pp. 107-130). Artmed.

Leão, S. M., Oliveira, I. M. F. F., \& Carvalho, D. B. (2014). O psicólogo no campo do bem-estar social: Atuação junto às famílias e indivíduos em situação de vulnerabilidade e risco social no Centro de Referência de Assistência Social (CRAS). Estudos e Pesquisas em Psicologia, 14(1), 264-289.

Lhullier, L. A. (Org.). (2013). Quemé a psicóloga brasileira? Mulher, Psicologia e Trabalho. Conselho Federal de Psicologia.

Lhullier, L. A., Roslindo, J. J., \& Moreira, R. A. L. C. (2013). Psicologia: Uma profissão de muitas e diferentes mulheres. Resultado preliminar. Conselho Federal de Psicologia.

Lopes, C.E. (2009).Oprojetodepsicologiacientífica deEdwardTolman. ScienticeStudia, 7(2),237-250.https://doi.org/ $10.1590 /$ S1678-31662009000200005

Macedo, J. P., \& Dimenstein, M. (2012). O trabalho dos psicólogos nas políticas sociais no Brasil. Avances en Psicología Latinoamericana, 30(1), 182-192.

Macedo, J. P., Sousa, A. P., Carvalho, D. M., Magalhães M. A., Sousa, F. M., \& Dimenstein, M. (2011). O psicólogo brasileiro no SUAS: Quantos somos e onde estamos? Psicologia em Estudo, 16(3), 479-489.

Macêdo, K. B., Heloani, R., \& Cassiolato, R. (2010). O psicólogo como trabalhador assalariado: Setores de inserção, locais, atividades e condições de trabalho. In S. M. Gondim, \& A. V. Bastos (Orgs.), O Trabalho do Psicólogo no Brasil (pp. 131-150). Artmed.

Motta, R. F., Castro, T. G. \& Pizzinato, A. (2015). A psicologia nos Centros de Referência de Assistência Social (CRAS): Um panorama das publicações científicas brasileiras de 2004 a 2014. Liberabit, 21(2), 341-348.

Nery, V. B. (2009). O trabalho de Assistentes Sociais e Psicólogos na Política de Assistência Social: Saberes e direitos em questão [Tese de doutorado, Pontifícia Universidade Católica de São Paulo]. TEDE Teses e Dissertações dos Programas de Pós-Graduação da PUC-SP. https://sapientia.pucsp.br/handle/handle/17987

Oliveira, I. F., \& Amorim, K. M. O. (2012). Psicologia e política social: O trato da pobreza como "sujeito psicológico". Psicologia Argumento, 30(70), 559-566.

Oliveira, I. F., Dantas, C. M. B., Solon, A. F. A. C. \& Amorin, K. M. O. (2011). A prática psicológica na proteção social básica do SUAS. Psicologia \& Sociedade, 23(spe.), 140-149. https://doi.org/10.1590/S0102-71822011000400017 
Oliveira, I. F., Oliveira, N. L. A., Nascimento, M. N. C., Araújo, R. L., Coelho-Lima, F., \& Amorin, K. M. O. (2014). Atuação dos psicólogos nos CRAS do interior do RN. Psicologia \& Sociedade, 26(spe.2), 103-112.

Porto, F. (2007). Debate: Mesa-redonda "Políticas Públicas, Estado e Sociedade": Formas de participação social. In Conselho Federal de Psicologia, IV Seminário Nacional de Psicologia e Políticas Públicas: Relatório (pp. 51-52). Conselho Federal de Psicologia; União Latino-Americana de Entidades de Psicologia.

Prates, J. C. (2014). Editorial: Políticas sociais e neodesenvolvimentismo: O desafio de formar para além de procedimentalismos. Textos e Contextos, 13(1), 1-8. https://doi.org/10.15448/1677-9509.2014.1.18364

Prefeitura de Porto Alegre. (2013). Fundação de Assistência Social e Cidadania: Apresentação. http://www2.portoalegre. rs.gov.br/fasc/default.php?p_secao=56

Raichelis, R. (2011). O trabalho e os trabalhadores do SUAS: O enfrentamento necessário na assistência social. In Secretaria Nacional de Assistência Social. Gestão do trabalho no âmbito do SUAS: Uma contribuição necessária (pp. 39-66). Ministério do Desenvolvimento Social e Combate à Fome

Reis, R. G., \& Cabreira, L. (2013). As políticas públicas e o campo: E o psicólogo com isso? Psicologia: Ciência e Profissão, 33(spe.), 54-65.

Santos, Y. G. (2014). As mulheres como pilar da construção dos programas sociais. Caderno CRH, 27(72), 479-494. https://doi.org/10.1590/S0103-49792014000300003

Secretaria Nacional de Assistência Social. (2004). Política Nacional de Assistência Social - PNAS. Ministério do Desenvolvimento Social e Combate à Fome.

Secretaria Nacional de Assistência Social. (2015). Censo SUAS 2014. Ministério do Desenvolvimento Social e Combate à Fome; Secretaria de Avaliação e Gestão da Informação.

Seixas, P. (2014). A formação graduada em Psicologia no Brasil: Reflexão sobre os dilemas em um contexto Pós$D C N$ [Tese de doutorado, Universidade Federal do Rio Grande do Norte]. Repositório Institucional UFRN. https://repositorio.ufrn.br/jspui/handle/123456789/17401

Seixas, P. S., \&Yamamoto, O. H. (2012). A inserção e a atuação profissional do psicólogo no campo das políticas sociais no Rio Grande do Norte. Psicologia Argumento, 30(70), 477-489. https://doi.org/10.7213/psicol.argum.6135

Senra, C. M. G., \& Guzzo, R. S. L. (2012). Assistência social e psicologia: Sobre as tensões e conflitos do psicólogo no cotidiano do serviço público. Psicologia \& Sociedade, 24(2), 293-299. https://doi.org/10.1590/ S0102-71822012000200006

Sposati, A. (2007). A menina Loas: Um processo de construção da Assistência Social (3a. ed.). Cortez.

Strauss, A., \& Corbin, J. (2008). Pesquisa Qualitativa: Técnicas e procedimentos para o desenvolvimento de Teoria Fundamentada (3a. ed.). Artmed.

Vasconcelos, E. M. (2011). Os psicólogos e sua inserção no SUAS: Da sensação inicial de perda de identidade ao reconhecimento de uma nova profissionalidade e de suas bases teóricas. In Secretaria Municipal de Assistência Social e Direitos Humanos de Resende (Org.), Cadernos de Assistência Social, vol. 1: Contribuições para a proteção básica e proteção especial (pp. 33-65). Secretaria Municipal de Assistência Social e Direitos Humanos de Resende.

Yamamoto, O. H. (2012). 50 anos de profissão: Responsabilidade social ou projeto ético-político? Psicologia Ciência e Profissão, 32(spe.), 6-17. https://doi.org/10.1590/S1414-98932012000500002

\section{Roberta Fin Motta}

Psicóloga e professora do curso de Psicologia da Pontifícia Universidade Católica do Rio Grande do Sul (PUCRS), Porto Alegre - RS. Brasil.

E-mail: robertafmotta@gmail.com

(1) https:// orcid.org/0000-0003-4074-0161

\section{Catheline Rubim Brandolt}

Mestranda em Psicologia pela Universidade Federal de Santa Maria (UFSM), Santa Maria - RS. Brasil.

E-mail: cathelinerb@gmail.com

(1) https://orcid.org/0000-0001-6000-8563 


\section{Adolfo Pizzinato}

Professor do curso de Psicologia Universidade Federal do Rio Grande do Sul (UFRGS), Porto Alegre - RS. Brasil. E-mail: adolfopizzinato@hotmail.com

(1) https://orcid.org/0000-0002-1777-5860

Agradecimentos à Fundação de Assistência Social e Cidadania (FASC), à Probolsa (PUCRS) e à Coordenação de Aperfeiçoamento de Pessoal de Aperfeiçoamento de Ensino Superior (Capes) e às psicólogas que efetivam as práticas na Assistência Social, pelo acolhimento, confiança e disponibilidade para esta pesquisa.

Endereço para envio de correspondência:

Rua Santana, 676, 802A, Santana. CEP: 90.040-144. Porto Alegre - RS. Brasil.

Recebido 25/03/2018

Aceito 25/04/2019

Received 03/25/2018

Approved 04/25/2019

Recibido 25/03/2018

Aceptado 25/04/2019

Como citar: Motta, R. F., Brandolt, C. R., \& Pizzinato, A. (2021). Trabalhadoras(es) do SUAS: Quem são as(os) psicólogas(os) da Proteção Social Básica (PSB). Psicologia: Ciência e Profissão, 41, 1-15. https://doi.org/10.1590/ 1982-3703003193409

How to cite: Motta, R. F., Brandolt, C. R., \& Pizzinato, A. (2021). Workers of Unique System of Social Assistance (SUAS): Who are the psychologists at Basic Social Protection (PSB). Psicologia: Ciência e Profissão, 41, 1-15. https://doi.org/10.1590/1982-3703003193409

Cómo citar: Motta, R. F., Brandolt, C. R., \& Pizzinato, A. (2021). Trabajadoras/es del Sistema Único de Asistencia Social (SUAS): Quiénes son las/los psicólogas/os de la Protección Social Básica (PSB). Psicologia: Ciência e Profissão, 41, 1-15. https://doi.org/10.1590/1982-3703003193409 